\title{
Blowtooth: A Provocative Pervasive Game for Smuggling Virtual Drugs through Real Airport Security
}

\author{
Ben Kirman, Conor Linehan and Shaun Lawson \\ Lincoln Social Computing Research Centre, School of Computer Science, University of \\ Lincoln, LN6 7TS, UK \\ \{bkirman|clinehan|slawson\} @ lincoln.ac.uk \\ Corresponding Author: Ben Kirman, bkirman@lincoln.ac.uk, tel: +44(0)1522837083
}

\section{Abstract}

In this paper we describe a pervasive game, Blowtooth, in which players use their mobile phones to hide virtual drugs on nearby airline passengers in real airport check-in queues. After passing through airport security, the player must find and recover their drugs from the innocent bystanders, without them ever realizing they were involved in the game. The game explores the nature of pervasive game playing in environments that are not, generally, regarded as playful or "fun". This paper describes the game's design and implementation as well as an evaluation conducted with participants in real airports. It explores the players' reactions to the game through questionnaire responses and in-game activity. The technologies used in Blowtooth are, intentionally, simple in order for the enjoyment of the game to be reliant more on the physical environment rather than the enabling technologies. We conclude that situating pervasive games in unexpected and challenging environments, such as international airports, may provide interesting and unique gaming experiences for players. In addition, we argue that pervasive games benefit most from using the specific features and nature of interesting real-world environments rather than focusing on the enabling technologies.

\section{Keywords}

Pervasive Games, Airports, Mobile Games, Non-players, Non-places, Provocative Games

\section{Introduction}

Pervasive games [10] are entertainment applications in which the real world is used as a virtual game-board. Such games have the potential to provide new and engaging experiences for players primarily by harvesting context information and incorporating it within the structure of a game [16]. Such games typically take the form of treasure hunts, where repetitive activities such as the daily commute to work, or the weekly shopping trip, may be enhanced via a fantasy narrative, or with a goal-directed game-world task. Example tasks include the visiting of new places or discovering of virtual objects in real space in order to gain points or access to new types of task [14].

The currently popular treasure hunt-style of pervasive games [e.g. 3,4] aim to use interesting game elements to enhance the supposed uninteresting, bland, or boring 
real-world environments of situated game-players. Such games are not typically designed to make use of environments that are already interesting or engaging, or that invoke strong or particular emotional reactions in people. In this paper we argue that the most interesting potential application of pervasive games, in fact, lies in the careful matching of game-world tasks to the particular features of the real-world environment that the player is currently experiencing. Pervasive games that do carefully assign tasks according to the unique features of a player's particular context have the potential to provide hugely enjoyable, novel and thoughtprovoking experiences.

Airports are environments with potential for situating mobile and, especially, casual games due to the large periods of interstitial time that are typically thrust onto travellers. However, no games have specifically exploited the uniqueness of the airport experience as the backdrop to a pervasive game. In this context, we set out to design a game that used simple technology and that exploited the unique nature of the airport experience. Blowtooth is specifically designed to exploit the affordances of international airports: environments in which people are subject to particularly high levels of intrusive surveillance and security monitoring, and that previous researchers have even identified as a place specifically unsuitable for pervasive games [11]. In everyday experience, high levels of surveillance can be both simultaneously thrilling and frightening; the possibility of harnessing these sensations in a game, or indeed any other art form, has great potential [1]. This paper, therefore, describes the application Blowtooth that has been developed to explore the limits of pervasive gaming in public spaces where constant surveillance has become the everyday norm [19]. In addition to demonstrating how the unique features of the real-world environment may enhance users' experience of pervasive games, Blowtooth, in concentrating heavily on the features of the social and physical environment of the airport, has the potential to provide commentary and the opportunity for reflection on the nature of that environment itself. As such it may be considered a critical game [6]. Critical games are designed to stimulate critical thinking about important social, political or physical structures. While Blowtooth was not designed solely with this purpose in mind, it has the potential to stimulate critical thinking on the nature of the airport environment. 


\section{Airports as Game Boards}

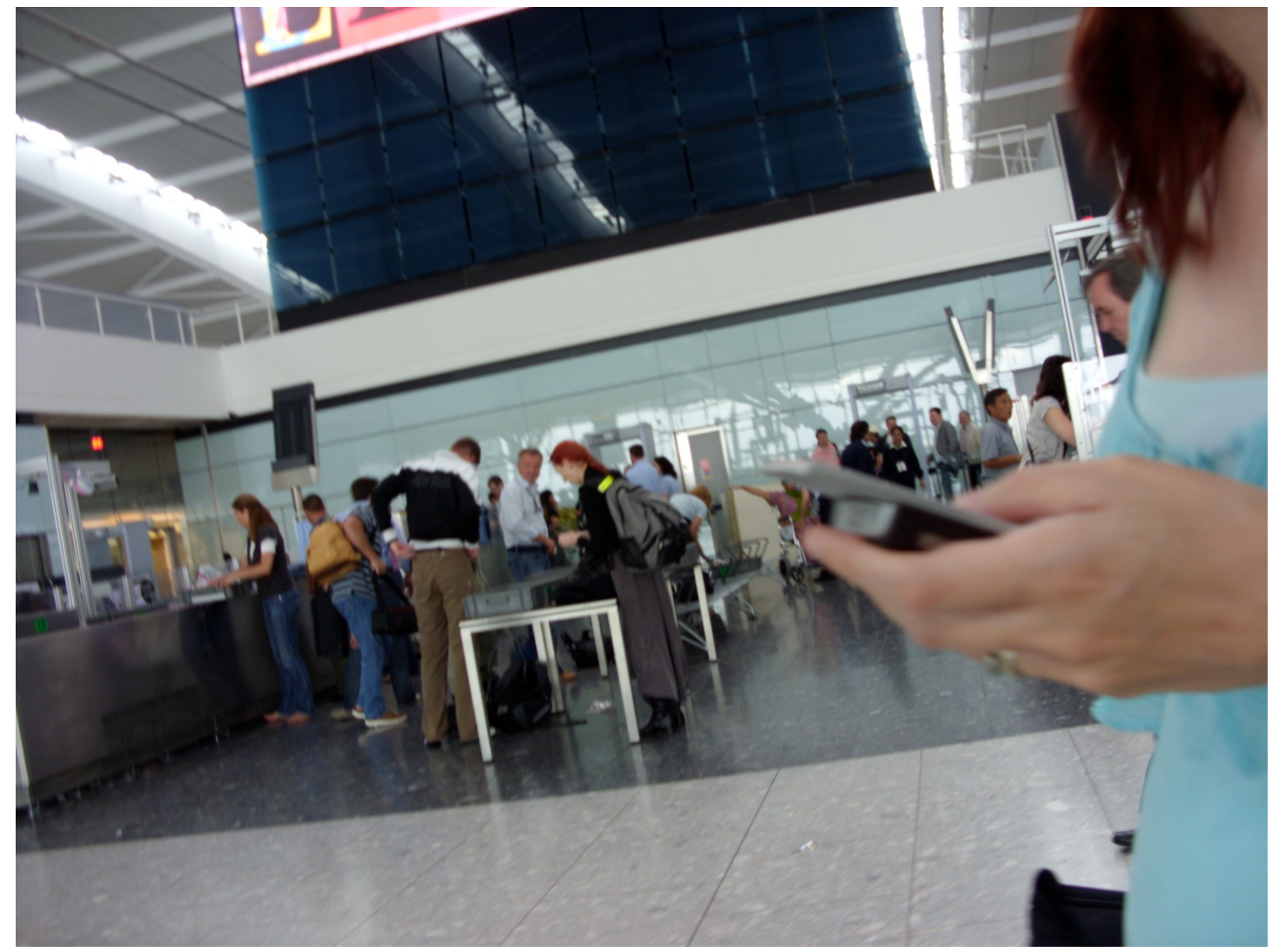

Fig. 1 - A participant playing Blowtooth inside the London Heathrow Terminal 5 HighSecurity Area

The airport (e.g. see Figure 1) constitutes a very different type of place to that which we usually inhabit in our everyday lives. Airports have attracted the attention of researchers from disciplines as diverse as anthropology, sociology, social psychology and political science, who have each attempted to explain the unique effect of the airport on those who use them. Airports have been described variously as national frontiers in the middle of a country, as cities, as transition spaces, places for commercial interchange, non-places, sites of surveillance, crossroads, symbols of mobility, and no-mans land (see [8] for in-depth discussion of these points). Many writers (e.g. [5]) have also talked about airports as constituting a non-place [2] i.e. a place that people pass through without meeting, and co-exist in without living together. Such places are typically inherently uniform to the point that they resist any emotional attachment or sense of belonging [7].

In addition, it is commonly noted that the airport is a place that generates tension and anxiety amongst travellers, staff and officials alike [e.g. 17]. Indeed, airports have been described as constituting the most authoritarian facility designed for the use of free civilians, an authoritative structure rivalled only by army bases and maximum-security prisons [8]. Kellerman describes the movement of passengers through the various security checks imposed by airport authorities in great detail [8] and discusses the impact of these checks on the experience of the international traveller. Throughout this analysis he draws attention to the ubiquitous presence and power of authority figures and the effect of causing tension and anxiety amongst travellers, staff and officials alike (see also [18]). Indeed, airports are places 
in which oppressive control technologies are implemented and people's expectations of privacy are altered. Authorities have extra powers to search and detain individuals and there are different expectations on travellers' behaviour than would be expected outside of this context.

\section{Games in Airports}

Since airports have a reputation as being a type of place defined by seriousness and stoicism, we decided to examine the appropriateness of using the airport as a context in which to situate a pervasive game.

Indeed, airports are already popular locations for playing games. While waiting for their flight, many passengers pass the time and alleviate their boredom by playing games on mobile devices such as phones or handheld consoles like the Nintendo DS, or by playing traditional card and board games. However, such play is almost certainly detached from the location - players are playing to pass time and use the "Magic Circle" of games [15] to take them out of the mundane reality of waiting for a flight. In essence, the fact that the game is played in an airport is not pertinent to how the game functions.

In reality, airports are in fact dynamic and exciting places - we share the airport environment with hundreds of strangers who are flying to many diverse locations and all co-located passengers are subject to the extraordinary levels of surveillance and scrutiny described above. Blowtooth as a game concept was borne out of the idea that we want to play games in airports to pass the time, but in such a way that it involves this very special and interesting environment. By designing a game that explicitly uses the airport in novel ways we wanted to make the boring activity of waiting for a flight more interesting and fun.

\section{Game Design}

Blowtooth is designed with a fictional narrative that is deliberately provocative given the environment in which it is set. Game-play involves the covert smuggling of a virtual cache of illegal drugs through airport security checks.

An overview of the game play is shown in Figure 2. A player starts the game once they arrive at the airport. From this moment, the game automatically plants small amounts of virtual drugs on unwitting fellow travellers in the local area (i.e. in the queue for checking-in luggage). When the player is about to go through airport security they must switch off their phone in order to initiate the second part of the game. In this mode, the player is forced to wait ten minutes to give the "patsies" (the term for other people who are carrying the drugs without realising it) a chance to go through the security screening process.

After this ten-minute wait, the player restarts their phone and is challenged to collect as many of their drug packages as they can before they board their plane. They can collect these packages by remembering who was near them during the first stage of the game, and finding and standing near them in order to re-collect their drugs. Points are awarded to play ers based on how many packages of drugs they manage to re-collect and how long it took them to do so. The people who carried the virtual drugs through airport security will never realise they were a part of the game. 


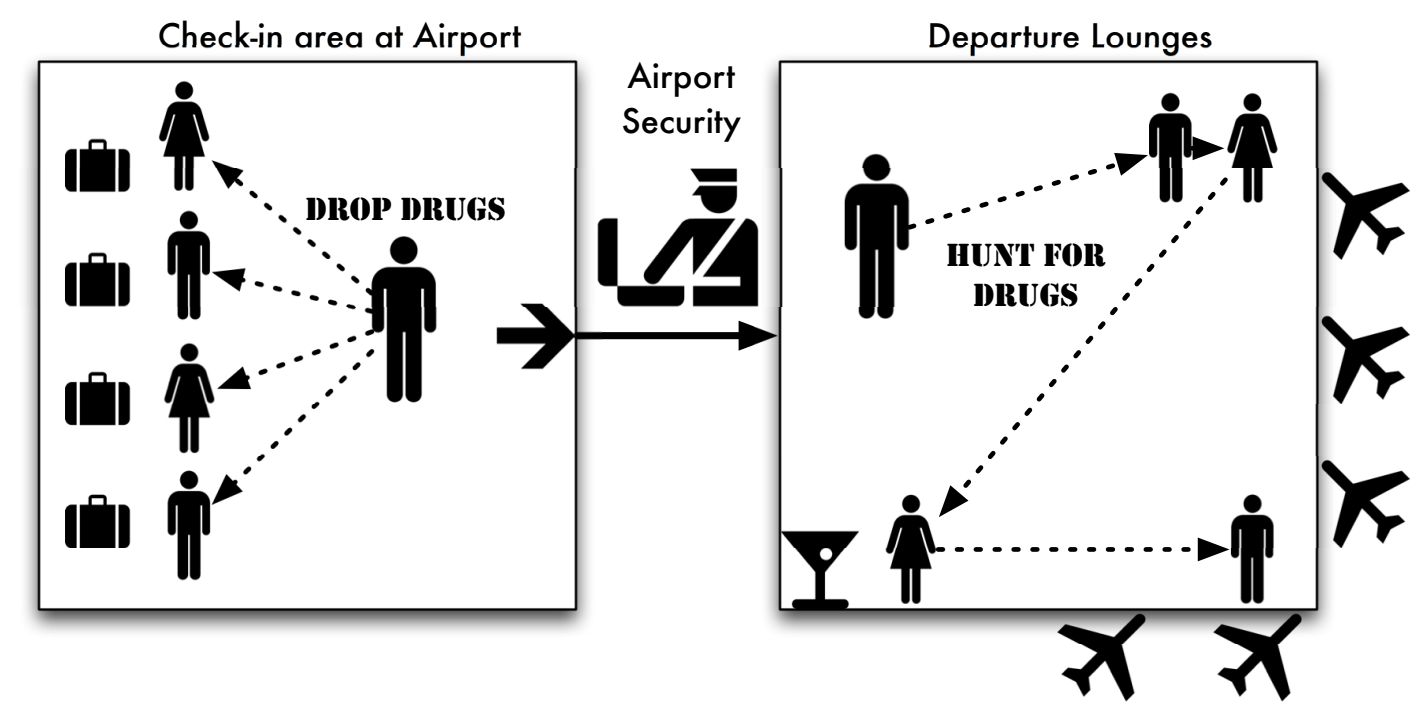

Fig 2. Gameplay through the real airport structures

The challenge for the player is to remember who was near them during the check-in period, and then be able to locate them in the busy departure area - such as in the public waiting area, the executive lounge, or in the bar. Since it is unlikely that a player will be able to retrieve all the drugs they have dropped (e.g. if drugs were dropped on someone in a rush who ran straight to their plane), the game is able to store the missing drugs on the game's Internet server. Then, on future plays, this player, or another Blowtooth player somewhere else in the world might be able to collect these missing drugs for extra points.

\section{Game Implementation}

In reality, of course, no drugs are involved in Blowtooth- everything is virtual and enabled by the Bluetooth capabilities of the player's mobile phone. The game has been implemented on Bluetooth-enabled smart-phones and exploits the fact that many people in airports also carry powered-on, Bluetooth-discoverable, mobile devices. A number of studies elsewhere have demonstrated the ubiquity of personal Bluetooth-enabled devices in everyday environments (see [19] for a short review). The game has been implemented using the Java Micro Edition (formerly the J2ME) and is available from http://www.blowtooth.com. The game is compatible with most MIDP 2.0 devices and works particularly well on Nokia Series 60 class phones (see Figure 3) 


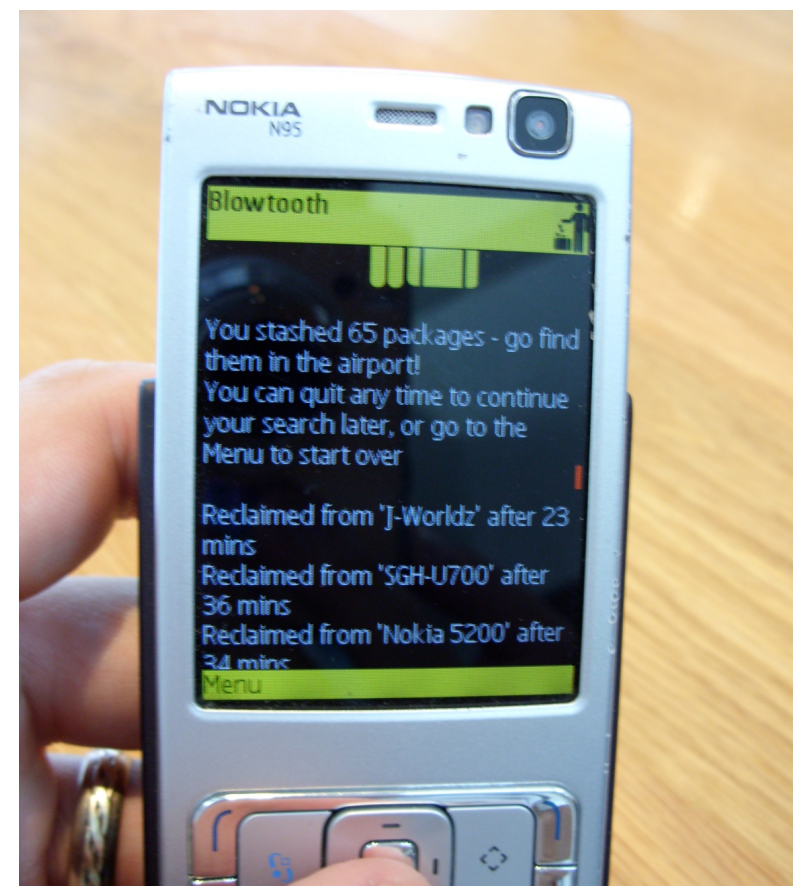

Fig. 3 - Blowtooth running on a Nokia N95 S60 device In the first stage of the game, during check-in at the airport, the game uses the Bluetooth hardware to send out a "device discovery" request. This request uses Bluetooth and therefore is short range $(\sim 10 \mathrm{~m})$. Each Bluetooth device within this range (e.g. phones, laptops, PDAs, etc.) will then contact the players phone to let it know that they are nearby. This contact includes information such as a Bluetooth name, device type and capabilities; and hardware address (HWADDR). The player's phone collects the list of all nearby hardware in internal memory. If a nearby Bluetooth device is switched off, or the user has disabled "discoverable" mode, it will not respond and therefore not be a part of the game. 


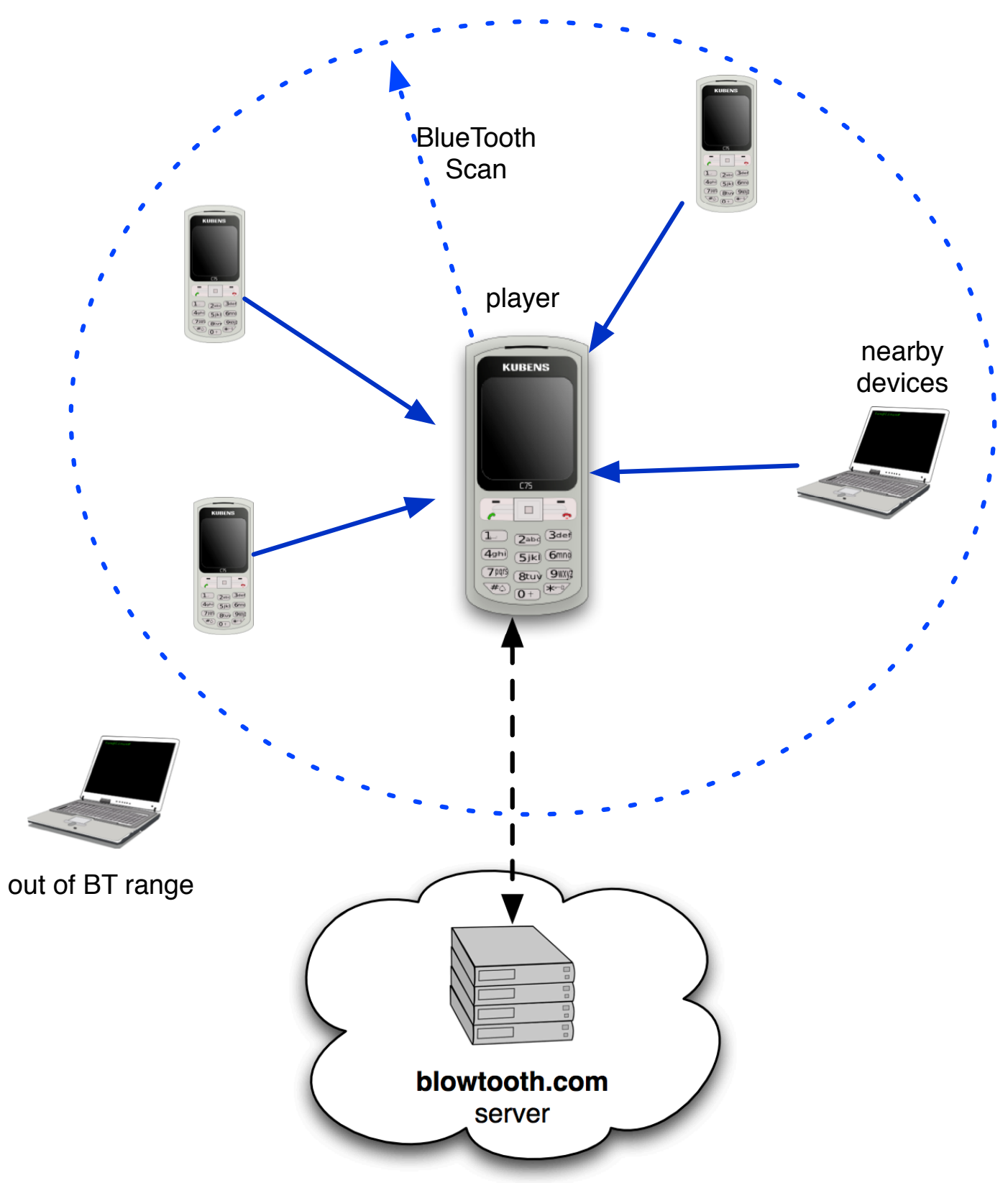

Fig. 4 - Bluetooth Scan for Nearby Devices

Next, the player's device contacts the game server (blowtooth.com) to see if any of these devices are already in the database. This is to see if a previous player has left drugs on the device and not been able to collect it. The game database uses a hashed version of the device HWADDR, so players and non-players involved in the game are completely anonymous (i.e. because of the algorithm it is impossible to look at the game database and determine what phone or person has been in the game). The phone continually scans and updates a list of nearby Bluetooth devices. In this way the player can move around and collect a large list of people (or "patsies"). Once the player switches off the phone (or manually ends the first stage), at the next available moment the game contacts the server and this internal list of nearby devices becomes stored on the database as containing drug packages. The 
player is then forced to wait ten minutes before starting the next stage; this gives the patsies time to disperse away from security.

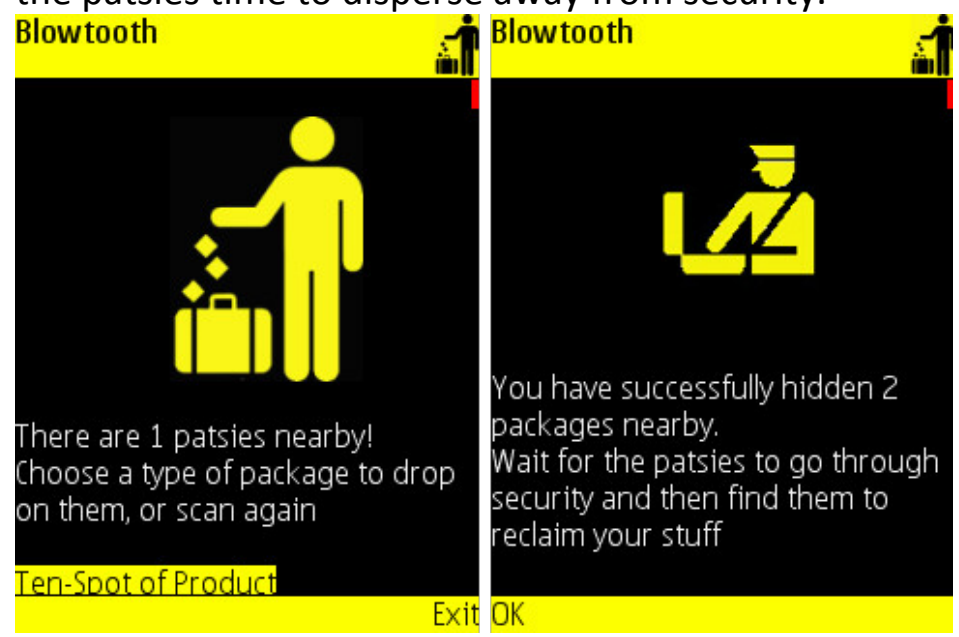

Fig 5. - Blowtooth in-game Screenshots

From this point on, the game continually scans for local devices. This time, instead of adding detected devices to an internal list, it checks them against the previous list of devices. If they are not found, it is disregarded. However, if a device does appear in the list, the player has managed to find a patsy and recover their drugs. The player is awarded points and shown a congratulatory message.

Importantly, the player's phone contacts the game server each time a patsy is found, and the server records the player's points. From this data, a global high score table is generated so that players can compare their smuggling efforts with those of all other players across the world. The server also then removes this patsy from the database that stores missing drugs.

An important fact about the implementation is that no data is stored on other devices without consent. The non-players have set their devices to be "discoverable", and it is because of this that Blowtooth is able to function. There is no security risk and there is absolutely no way for the game to interfere with these other devices. Also, since there is no actual drugs involved, or any interference with other people, the game is completely safe to play in airport security without breaking any laws. Any feelings of danger or risk are entirely a part of the internalised game narrative the players create for themselves.

Similarly important is the choice of technologies for the implementation of Blowtooth. The game relies only on basic Bluetooth scanning functionality that is a standard feature of the vast majority of J2ME enabled devices. The reason for this is twofold - first, to allow the greatest compatibility with devices, and secondly, to highlight that the most important feature of pervasive games is the environment of play. The value of Blowtooth as a game is the place in which it is played, not the complexity of its technology. Pervasive games are not just excuses to try new technology, but allow us to explore new contexts for human computer interactions.

\section{Evaluation}

This study investigated a number of themes relevant to pervasive game playing in unique and challenging environments. Specifically, we expected the drug-smuggling narrative of the Blowtooth game to create a highly engaging experience. In the 
context of a high-security airport environment, we expected that the playing of Blowtooth would affect participants' self-reported levels of anxiety.

We were also interested in whether participants felt comfortable engaging with a narrative based on illegal activity whilst in a high-security environment. In other words; did the matching of game task to the high-security real-world environment result in a game that participants wanted to play, or enjoyed playing.

A further issue of interest relates to the potential of Blowtooth as a critical game; we were interested whether the security-conscious narrative of the game affected participant's experience of the high-security airport environment. Specifically, we expected the drug-smuggling narrative of the Blowtooth game to affect participants' awareness of both security and their fellow passengers.

We were also interested in whether participants felt comfortable with the requirement to interact with non-players, particularly in terms of the requirement to seek out and find tagged fellow passengers after they had passed through security checks.

In order to evaluate these issues, six participants were recruited from personal contacts and acquaintances of the authors. All participants were travelling internationally within two weeks of the trial dates. These participants downloaded and played the Blowtooth game while travelling through an airport, before answering a questionnaire featuring both open-ended questions regarding the participants' experiences of the game and context, plus two separate quantitative scales. The first of these presented a number of questions taken from an established questionnaire that was developed as a part of the EU "FUGA" project aimed at developing tools for measuring and evaluating player enjoyment in games [13]. The second, a short 12-item questionnaire, was designed to sample three factors; Anxiety, Security Awareness and Awareness of Other Passengers.

\section{Results}

In order to evaluate whether participants were comfortable with, or indeed enjoyed, playing a game with a narrative based on illegal activities while in a high-security environment, a questionnaire was distributed to all six participants who played the game. This questionnaire consisted of eight questions taken from the Games Experience Questionnaire (GEQ) [13] designed to measure enjoyment of digital games and answered via a 5-point Likert scale.

Four of the seven factors in the GEQ were identified as useful in the current context. These were Competence, Positive Affect, Frustration and Negative Affect. Positive affect refers to positive emotions such as happiness and enjoyment, while negative affect refers to negative emotions such as boredom and tiredness. Two questions were chosen from the GEQ to probe for each of the four factors. Results of the six game players' responses to these questions are presented in table 1.

Table 1. Mean scores for Competence, Positive Affect, Frustration and Negative Affect in Blowtooth players.

\begin{tabular}{|c|c|c|c|}
\hline Competence & Positive Affect & Frustration & Negative Affect \\
\hline 3.16 & $3.75(\mathrm{SD}=1.21)$ & $\begin{array}{c}1.41 \\
(\mathrm{SD}=1.02)\end{array}$ & $1.66(\mathrm{SD}=1.69)$ \\
$(\mathrm{SD}=1.16)$ & & \\
\hline
\end{tabular}


Table 1 illustrates that the participants who played the Blowtooth game reported high levels of competence and positive affect, while also reporting low levels of frustration and negative affect. Thus, it appears participants were quite content to play the Blowtooth drug smuggling game in the high-security environment of an international airport. This result supports the assumption suggesting that matching pervasive game content to the unique features of a challenging environment can produce an enjoyable experience for game players.

The current study also investigated the effect that playing a security conscious game in a high-security environment had on participants' perceptions of that environment. In order to do this, a questionnaire was presented to the six participants who played the Blowtooth game. The questionnaire presented 12 questions that probed for three overall factors; security awareness, anxiety and awareness of fellow passengers. Questions were answered via a 5-point Likert scale.

Table 2. Mean scores reported for security awareness, anxiety and awareness of fellow passengers.

\begin{tabular}{|c|c|c|}
\hline $\begin{array}{c}\text { Security } \\
\text { awareness }\end{array}$ & Anxiety & $\begin{array}{c}\text { Awareness of fellow } \\
\text { passengers }\end{array}$ \\
\hline $2.75(\mathrm{SD}=1.25)$ & $2.5(\mathrm{SD}=1)$ & $2.75(\mathrm{SD}=0.95)$ \\
\hline
\end{tabular}

Table 2 suggests that participants who played Blowtooth did not report very high ratings of anxiety, despite the provocative nature of the game narrative, and the high security environment. In addition, participants did not report particularly high or low levels for awareness of security personnel or awareness of fellow passengers. This result is surprising, due to the game task, which required participants to interact with these groups in ways that they would not normally.

Results of these short questionnaires are certainly surprising, as it was envisioned that Blowtooth would lead to anxiety in game players, and increased awareness and scrutiny of both security staff and the behaviour of other passengers. However, the sample size $(n=6)$ is very small, so responses to open-ended questions were deemed equally, if not more valuable. The open-ended questions presented to participants probed a number of topics.

The principal aim of the study was to investigate whether the matching of game narrative and game tasks to a unique and challenging environment would create an engaging and enjoyable experience for game players. Participants generally reported that they enjoyed the drug-smuggling narrative of the game. Participant 1 reported, "I liked the names for items and people. They made it fun." Participant 2 stated, "I enjoyed the theme, it gave it a purpose," while Participant 6 reported that the narrative "works, because you are at an airport and it fits together."

We were interested in whether playing the game affected participants' behaviour and the emotions they experienced while at the airport. While participants were, "very aware it's just a game," they typically reported some anxiety caused by playing Blowtooth. Participant 2 reported that they "left the game running whilst going through security so was slightly concerned if they chose to search my bag I would have to explain what it was doing." Participants 4 and 5 made sure that their phone was locked when passing through security so that staff would not see the distinctive Blowtooth graphics (See Figure 5). Indeed, four of the six participants reported making minor adjustments to their behaviour (e.g. ensuring that their game screen, 
with the striking graphics, could not be seen by security personnel) due to playing the game.

We were interested in whether Blowtooth provoked participants to think more critically about the nature of airports. Three participants reported that they noticed interesting aspects of the airport environment that they had not previously noticed. Specifically, participant 1 "noticed the ways the different airports 'herd' the passengers to their gates. Some get you there soon after the security and you wait there, others have a more general waiting area," while participant 2 "took more notice of where other planes were taking off from, also looked for places where large groups of people gathered." It appears that playing Blowtooth provoked these participants into more critical thinking about their surroundings.

We were interested in whether Blowtooth provoked participants to think more critically about the nature of play and the idea of playing games in high security environments. None of the participants reported any unease with the drugsmuggling game narrative, nor did any of the six Blowtooth players report feeling that the airport was an unsuitable venue for pervasive gaming. Indeed, none of the participants reported that they were worried about breaking the law while playing the game. When asked whether there was any environment in which it would be inappropriate to play pervasive games, participants provided a number of imaginative responses such as funeral homes, churches, hospitals, saunas, theatres/cinemas, libraries and courtrooms.

As the game required participants to interact with other, unsuspecting, passengers, we were interested in what effect this requirement would have on participants' interactions with those fellow passengers. Participant 2 reported that:

"it was fun guessing who the phones belonged to, for example sitting in a restaurant having my lunch 2 patsies were located just as two men entered the restaurant."

Participant 6 says:

"I noticed people i'd seen before more frequently even if they weren't a bluetooth person."

Participants did not appear to be worried about any ethical implications to do with playing such games, with participant 5 even requesting "a direction finder or distance finder to know how "close" to a package I was."

Overall, player comments appear to suggest that Blowtooth was an engaging, fun, and thought-provoking experience that, importantly, "really helped relieve boredom," related to international travel.

\section{Discussion}

Our research on Blowtooth has investigated whether people feel comfortable engaging with a game that is based on an explicitly illegal activity whilst in a highsecurity environment. Those participants in our trial who played Blowtooth reported being content to engage in virtual drug smuggling at airports and enjoyed doing so. In addition, half of those participants who played the Blowtooth game commented that, as a result of playing the game, they noticed specific features of the airport environment of which they had not previously been aware. 
We have also investigated whether the security-conscious narrative of the game altered people's experience of the high-security airport environment. Surprisingly, participants who played the Blowtooth game did not report high levels of either anxiety or awareness of fellow passengers. It appears that playing the game actually led participants to being less aware of their surroundings and being more relaxed. Of course, it is possible that only people who were already comfortable with the idea of playing a drug smuggling game in an airport volunteered to participate in the user evaluation. However, the finding that participants who played the Blowtooth game reported low levels of anxiety is remarkably consistent across both questionnaires used in the study. Thus, it is possible that engaging in subversive games in tense environments actually has the result of relaxing those game players.

In this paper we have argued that the most interesting potential application of pervasive games lies in the careful matching of game-world activity to the unique or emotion-provoking features of the real-world environment that the player is experiencing. The finding that Blowtooth provoked participants to think more critically about both the nature of airports, and the idea of playing games in high security environments, is exciting, as it suggests that the process of carefully creating pervasive game tasks that take advantage of the unique and challenging elements of "taboo" environments creates the possibility to construct engaging, thoughtprovoking critical games about those environments.

The issue of context is extremely important - when developing games and other computing applications that are meant to be used when mobile, the drive to generalise experience across contexts may be counter-productive. A pervasive game developed for generalised locations misses the unique values inherent in each different place. The special social and environmental context of airports is what makes Blowtooth an interesting game, despite the fact the game could be played anywhere.

A related point is that of technology. As the field of pervasive computing continues to develop, it creates new opportunities for exciting technologies to be used in applications. However, the value of pervasiveness is not one intrinsic to the new technologies themselves. The value appears when appropriate technologies are used in appropriate places. Blowtooth was intentionally designed using simple and "old" technology by academic standards (Bluetooth), yet this technology is adequate to provide the pervasive experience the application required. The value of Blowtooth is in its application of technology in context, rather than the technology itself.

We are aware that Blowtooth raises some interesting privacy and ethical implications. It is clearly intentional that Blowtooth has an edgy and a risqué nature. However it is delivered and presented in a playful and tongue-in-cheek manner through its user interface, graphics and narrative. The notion of using 'non-players' as part of a game mechanic is actually a common theme in pervasive games that has been explored, for instance, in the EU FP6 iPerG project [12]. Indeed, none of the participants in the current study expressed any concern over the use of non-players. In fact, some players expressed a wish to have more powerful tools for finding those people after they had passed through security.

In summary, it appears that a provocatively themed pervasive game played with strangers in a highly secure and invasive location can facilitate a positive gameplaying experience. This emphasises the untapped potential of pervasive games to 
provide engaging and thought-provoking experiences by locating technologically simple games in already-interesting environments. Thus, environments that at first seem to be entirely unsuitable locations for pervasive game play, may, in fact, be the ideal locations.

\section{Acknowledgements}

A preliminary, unpublished, version of this paper was presented at alt.CHI in the 2010 ACM Conference on Human Factors in Computing Systems. We are grateful to the alt. $\mathrm{CHI}$ community for the valuable discussion and ideas that have contributed to making this work stronger.

\section{References}

1. Albrechtslund, A. and Dubbeld, L. (2005) The plays and arts of surveillance: Studying surveillance as entertainment. Surveillance \& Society, 3, 2, 216-221.

2. Auge, M. Non-places: An Introduction to an Anthropology of Supermodernity (1995), Verso: London.

3. Benford, S., Flintham, M., Drozd, A., Anastasi, R., Rowland, D. et al. (2004) Uncle Roy All Around You. In Proc. Advances in Computer Entertainment, ACM.

4. Cheok, A., Goh, K., Farbiz, F., Fong, S., Teo, S., Li, Y., and Yang, X. (2004) Human Pacman: A mobile, wide-area entertainment system based on physical, social and ubiquitous computing. Personal \& Ubiquitous Computing 8, 2, 71-81.

5. Crang, M. (2002) Between places: producing hubs, flows and networks. Environment and Planning A, 34, 569-574.

6. Flanagan, M. (2009) Critical Play: Radical Game Design. MIT press

7. Gentile, A.P. Reinventing Airspace: Spectatorship, fluidity, intimacy at PEK T3 (2009). J of Architecture, City \& Environment, 4, 10, 9-19.

8. Kellerman, A. (2008) International Airports: Passengers in an Environment of Authorities. Mobilities, 3,1

9. Kitson, F. (2005) Mobile media: Making it a reality ACM Queue, 3, 4. 38-47.

10. Montola, M., Stenros, J. and Waern, A. (2009) Pervasive Games: Theory and Design, Morgan Kaufmann

11. Montola, M. (2005) Exploring the edge of the magic circle: Defining pervasive games. In Proceedings of DAC Conference.

12. Niemi, J., Sawano, S., and Waern, A. (2005) Involving nonplayers in pervasive games. In Proc 4th conference on Critical computing.

13. Poels, K, deKort, Y.A.W, and Ijsselstein, W.A. (2007) Game Experience Questionnaire. Project deliverable for the EU IST project the fun of gaming.

14. Reid, J. (2008) Design for coincidence: incorporating real world artifacts in location based games. DIMEA '08: Proceedings of the 3rd international conference on Digital Interactive Media in Entertainment and Arts, 18-25.

15. Salen, K. and Zimmerman, E. (2003) Rules of Play: Game Design Fundamentals, MIT Press

16. Sotamaa, O. (2002) All the World's a Botfighter Stage: Notes on LocationBased Multi-User Gaming. Tampere University Press, Tampere 
17. Szyliowicz, J.S. (2004) Aviation security: Promise or reality? Studies in Conflict and Terrorism, 27, 47-63.

18. Wales, R., O'Neill, J., Mirmalek, Z. (2002) Ethnography, customers, and negotiated interactions at the airport. IEEE Intelligent Systems, 17, 5, 15-23.

19. Wood, D.M. (ed.) (2006) A Report on the Surveillance Society. London: Information Commissioner's Office.

20. Yoneki, E., and Crowcroft, J. (2008) Wireless Epidemic Spread in Dynamic Human Networks. Bio-Inspired Computing and Communication, LNCS 5151, Springer. 